\title{
RELATIONSHIPS BETWEEN WELLNESS STATUS AND PERCEIVED TRAINING LOAD ON DAILY AND WEEKLY BASES OVER A BASKETBALL SEASON
}

\author{
Filipe Manuel Clemente ${ }^{1,2}$, Sarah da Glória Teles Bredt ${ }^{3}$, Gibson Moreira Praça ${ }^{3}$, \\ Emanuel Duarte ${ }^{4}$, and Bruno Mendes 5 \\ ${ }^{1}$ Escola Superior Desporto e Lazer, Instituto Politécnico de Viana do Castelo, \\ Viana do Castelo, Portugal \\ ${ }^{2}$ Instituto de Telecomunicações, Delegação da Covilhã, Portugal \\ ${ }^{3}$ Universidade Federal de Minas Gerais, Belo Horizonte, Minas Gerais, Brazil \\ ${ }^{4}$ Benfica LAB, Sport Lisboa e Benfica, Lisboa, Portugal \\ ${ }^{5}$ University of Lisbon, Faculty of Human Kinetics, Lisbon, Portugal
}

Original scientific paper

DOI $10.26582 / \mathrm{k} .52 .1 .18$

\begin{abstract}
:
This study aimed to determine the relationships between internal training load (session-RPE) and wellness status (delayed onset muscle soreness - DOMS, stress, fatigue, and sleep quality) on both daily and weekly bases over a basketball season. Fifteen professional basketball players provided their wellness status and perceived training load for all training sessions and matches over a season. Daily correlations were based on the perceived load of a training session/match and the wellness status rated on the following day (before the next session). Weekly correlations were based on the sum of all ratings of the week for each variable. Results showed that DOMS and fatigue presented higher correlations with session-RPE than stress and sleep quality on both daily and weekly analyses. Daily measures presented small-to-moderate correlations between the perceived training load and wellness categories over the months. Weekly correlations increased (moderate-tolarge) for all wellness categories, except for stress. We concluded that DOMS and fatigue are more associated to session-RPE than stress and sleep quality in professional basketball players. Weekly analyses may help coaches to better understand the impact of training load on athletes' physical wellness (DOMS and fatigue), possibly due to a delayed physiological response to training load.
\end{abstract}

Key words: athletic performance, basketball, training load monitoring, session-RPE, wellness

\section{Introduction}

Training load can be analyzed as external (i.e., absolute measures of work performed by athletes during training and competition sessions; for example, total distance covered, number of accelerations performed) or internal load (acute biological responses to a given physical stimulus during training and competition) (Bourdon, et al., 2017). Monitoring internal training load is important to ensure the individualization of training process (Hooper \& Mackinnon, 1995), since athletes may respond differently to the same external training load. Internal load can be assessed by variables such as heart rate responses, blood lactate concentration, hormonal concentrations, and rating of perceived exertion (RPE) (Halson, 2014). In addition, training and competition processes may represent stressful factors for athletes, due to high and congested training loads experienced especially during the competitive phase (Moreira, et al., 2008). Therefore, an inadequate training load may impair athletes' wellness status and sport performance (Mielgo-Ayuso, Zourdos, Clemente-Suárez, Calleja-González, \& Shipherd, 2017; Thorpe, et al., 2017), contributing to overtraining and injuries (Halson, 2014). However, few studies investigated the relationship between the internal load and wellness status aspects (Clemente, et al., 2017; Malone, Lovell, Varley, \& Coutts, 2017; Thorpe, et al., 2015), none of them in professional basketball. Information on this association may help coaches to understand the impact of training process on athletes' well-being and physical condition.

Internal load can be measured by the sessionRPE, which is a psychophysiological easily-obtainable variable (Foster, et al., 2001). Session-RPE has 
been shown to be significantly correlated to heart rate responses (Edwards' training load) (Manzi, et al., 2010) and to the external load measured by accelerometers (Scanlan, Neal, Tucker, \& Dalbo, 2014) in professional basketball players. Athletes' wellness status may be influenced by physical and psychological variables, such as delayed onset muscle soreness (DOMS), stress, fatigue, and sleep quality (Hooper questionnaire categories) (Clemente, et al., 2017; Haddad, et al., 2013; Hooper \& Mackinnon, 1995). Clemente et al. (2017) reported small correlations (Spearman negative correlations from 0.041 to 0.238 ) between daily session-RPE and wellness categories in soccer players. Also, Thorpe et al. (2015) reported partial correlations of 0.04 to 0.1 (except for fatigue category - 0.51). This result suggests that wellness status may be influenced by other factors (e.g., out-of-training issues, social/affective relationships) and that the internal load plays a minor role in determining wellness. However, it is known that decreases in performance and biological alterations may occur up to 72 hours after matches (Cormack, Newton, \& McGuigan, 2008; Ispirlidis, et al., 2008). Therefore, daily analyses may not show a true association between training load and wellness, which may be overcome by analyzing a longer time interval, such as weeks. Furthermore, although some studies on basketball reported increased levels of stress during the competitive phase (Moreira, et al., 2008) and relationships between monotony of training and training strain (Anderson, Triplett-McBride, Foster, Doberstein, \& Brice, 2003), the differences between sports (soccer vs. basketball) may lead to different relationships between training load and wellness.

Based on the above-mentioned issues, this study aimed to determine the relationships between internal training load (session-RPE) and wellness status (Hopper wellness categories - DOMS, stress, fatigue, and sleep quality) on both the daily and weekly basis over a basketball season.

\section{Material and methods}

\section{Experimental approach}

This study presented a descriptive approach to investigating athletes' session-RPE and wellness status (Hooper questionnaire - stress, fatigue, muscle soreness DOMS, and sleep quality) over a season. Training sessions were planned and executed by coaches and researchers did not interfere in the process. The observed season was split in eleven months, from August 2016 to June 2017, comprising 42 weeks in total (Table 1).

\section{Participants}

Fifteen professional basketball players from a club that won the first league national championship of a European country (age 27.1 \pm 5.2 years; body height $195.3 \pm 9.9 \mathrm{~cm}$; body mass $97.2 \pm 13.1 \mathrm{~kg}$; basketball experience $7.6 \pm 5.6$ years), participated in this study. All players had been familiarized with research procedures as part of their regular practice routine (session-RPE and Hooper questionnaire). The ethical standards of the Declaration of Helsinki for studies with humans were respected.

\section{Procedures}

Players classified their effort from 1 (very light activity) to 10 (maximal exertion) according to the CR-10 Borg scale (Borg, 1998) approximately 30 minutes after each training session or match. Ratings were multiplied by either the session or match total duration in minutes (Foster, et al., 2001), resulting in session-RPE (perception of session load).

The Hooper questionnaire (Hooper \& Mackinnon, 1995) of four categories (delayed onset muscle soreness [DOMS], stress, fatigue, and sleep quality) was rated approximately 30 minutes before each training session or match. Each category presents seven classifications. For DOMS, stress, and fatigue levels, 1 means very, very low, and 7 means very, very high. For sleep quality, 1 means very, very good, and 7 means very, very bad (Clemente, et al., 2017). The sum of the four categories gives the Hooper Index (Haddad, et al., 2013). The lower the index, the better the wellness status.

The CR-10 and Hooper questionnaire were rated individually using a computer tablet (Surface Pro 3, Microsoft, USA) with an app designed for these two scales. This approach reduces the possibility of hearing or observing ratings of others, and increases answers' accuracy (Malone, et al., 2015). The weekly session-RPE, stress, fatigue, muscle soreness, sleep quality, and Hooper Index (HI) was the summation of values of all training sessions and matches of a week.

Table 1. Total number of weeks, training sessions, and matches over the season

\begin{tabular}{|c|c|c|c|c|c|c|c|c|c|c|c|}
\hline & August & September & October & November & December & January & February & March & April & May & June \\
\hline Weeks & 1 & 5 & 4 & 4 & 5 & 4 & 4 & 5 & 4 & 4 & 2 \\
\hline $\begin{array}{l}\text { Training } \\
\text { sessions }\end{array}$ & 3 & 35 & 26 & 21 & 26 & 19 & 22 & 28 & 22 & 22 & 11 \\
\hline Matches & 0 & 8 & 7 & 8 & 7 & 8 & 7 & 9 & 5 & 7 & 3 \\
\hline
\end{tabular}




\section{Statistical procedures}

Spearman correlations were calculated between daily and weekly session-RPE and wellness categories (ordinal scales) (O'Donoghue, 2012). The magnitude of correlations was classified as trivial (rho $\leq .1)$, small $(.1<$ rho $\leq .3)$, moderate $(.3<$ rho $\leq .5)$, large $(.5<$ rho $\leq .7)$, very large $(.7<$ rho $\leq .9)$, and nearly perfect (rho $\geq 9$ ) (Hopkins, Hopkins, \& Glass, 1996). All statistical analyses were performed using the Statistical Package for Social Sciences software (version 23.0, IBM, USA). Statistical significance was set at $\mathrm{p} \leq .05$.

\section{Results}

Table 2 presents mean $(95 \%$ confidence intervals) values of daily and weekly Hooper catego- ries of each month. Hooper Index was calculated to present an overall idea of athletes' wellness over the season. Figures 1 and 2 present mean $(95 \%$ confidence intervals) values of daily and weekly sessionRPE and Hooper Index over the months.

Table 3 presents the correlations between session-RPE and Hooper categories on both the daily and weekly basis. Small-to-moderate correlations were found between both the daily sessionRPE and Hooper categories over the months. For weekly values, there were moderate-to-large correlations between session-RPE and DOMS, and session-RPE and fatigue, while there were small-to-moderate correlations between sessionRPE and sleep, and session-RPE and stress over the season.

Table 2. Mean (95\% confidence interval) daily and weekly wellness categories over the season

\begin{tabular}{|c|c|c|c|c|c|c|c|c|c|c|c|}
\hline & August & September & October & November & December & January & February & March & April & May & June \\
\hline \multicolumn{12}{|l|}{ Daily assessment } \\
\hline A.U. Daily-DOMS & $\begin{array}{c}3.45 \\
{[3.12 ; 3.78]}\end{array}$ & $\begin{array}{c}2.82 \\
{[2.71 ; 2.93]}\end{array}$ & $\begin{array}{c}2.53 \\
{[2.42 ; 2.64]}\end{array}$ & $\begin{array}{c}2.24 \\
{[2.14 ; 2.34]}\end{array}$ & $\begin{array}{c}2.30 \\
{[2.20 ; 2.40]}\end{array}$ & $\begin{array}{c}2.33 \\
{[2.21 ; 2.45]}\end{array}$ & $\begin{array}{c}2.75 \\
{[2.64 ; 2.87]}\end{array}$ & $\begin{array}{c}2.44 \\
{[2.34 ; 2.54]}\end{array}$ & $\begin{array}{c}2.65 \\
{[2.54 ; 2.77]}\end{array}$ & $\begin{array}{c}2.58 \\
{[2.48 ; 2.68]}\end{array}$ & $\begin{array}{c}2.51 \\
{[2.32 ; 2.70]}\end{array}$ \\
\hline A.U. Daily-Sleep & $\begin{array}{c}3.32 \\
{[2.93 ; 3.71]}\end{array}$ & $\begin{array}{c}2.95 \\
{[2.80 ; 3.10]}\end{array}$ & $\begin{array}{c}2.61 \\
{[2.48 ; 2.74]}\end{array}$ & $\begin{array}{c}2.42 \\
{[2.28 ; 2.55]}\end{array}$ & $\begin{array}{c}2.41 \\
{[2.28 ; 2.55]}\end{array}$ & $\begin{array}{c}2.37 \\
{[2.22 ; 2.51]}\end{array}$ & $\begin{array}{c}2.36 \\
{[2.23 ; 2.48]}\end{array}$ & $\begin{array}{c}2.37 \\
{[2.25 ; 2.48]}\end{array}$ & $\begin{array}{c}2.44 \\
{[2.29 ; 2.58]}\end{array}$ & $\begin{array}{c}2.24 \\
{[2.12 ; 2.36]}\end{array}$ & $\begin{array}{c}2.31 \\
{[2.11 ; 2.51]}\end{array}$ \\
\hline A.U. Daily-Fatigue & $\begin{array}{c}3.28 \\
{[3.05 ; 3.52]}\end{array}$ & $\begin{array}{c}2.99 \\
{[2.88 ; 3.10]}\end{array}$ & $\begin{array}{c}2.69 \\
{[2.58 ; 2.80]}\end{array}$ & $\begin{array}{c}2.40 \\
{[2.30 ; 2.51]}\end{array}$ & $\begin{array}{c}2.34 \\
{[2.22 ; 2.45]}\end{array}$ & $\begin{array}{c}2.48 \\
{[2.36 ; 2.60]}\end{array}$ & $\begin{array}{c}2.85 \\
{[2.72 ; 2.97]}\end{array}$ & $\begin{array}{c}2.54 \\
{[2.44 ; 2.64]}\end{array}$ & $\begin{array}{c}2.70 \\
{[2.58 ; 2.82]}\end{array}$ & $\begin{array}{c}2.60 \\
{[2.50 ; 2.70]}\end{array}$ & $\begin{array}{c}2.42 \\
{[2.24 ; 2.60]}\end{array}$ \\
\hline A.U. Daily-Stress & $\begin{array}{c}2.00 \\
{[1.72 ; 2.28]}\end{array}$ & $\begin{array}{c}2.25 \\
{[2.10 ; 2.40]}\end{array}$ & $\begin{array}{c}1.88 \\
{[1.76 ; 2.00]}\end{array}$ & $\begin{array}{c}1.97 \\
{[1.81 ; 2.13]}\end{array}$ & $\begin{array}{c}1.81 \\
{[1.66 ; 1.97]}\end{array}$ & $\begin{array}{c}1.86 \\
{[1.71 ; 2.00]}\end{array}$ & $\begin{array}{c}1.93 \\
{[1.78 ; 2.09]}\end{array}$ & $\begin{array}{c}1.47 \\
{[1.38 ; 1.56]}\end{array}$ & $\begin{array}{c}1.51 \\
{[1.41 ; 1.62]}\end{array}$ & $\begin{array}{c}1.42 \\
{[1.35 ; 1.50]}\end{array}$ & $\begin{array}{c}1.40 \\
{[1.28 ; 1.52]}\end{array}$ \\
\hline \multicolumn{12}{|l|}{ Weekly assessment } \\
\hline A.U. Weekly-DOMS & $\begin{array}{c}14.11 \\
{[11.58 ; 16.64]}\end{array}$ & $\begin{array}{c}15.38 \\
{[14.32 ; 16.44]}\end{array}$ & $\begin{array}{c}14.00 \\
{[12.59 ; 15.41]}\end{array}$ & $\begin{array}{c}10.98 \\
{[9.93 ; 12.03]}\end{array}$ & $\begin{array}{c}11.74 \\
{[10.70 ; 12.78]}\end{array}$ & $\begin{array}{c}11.60 \\
{[10.46 ; 12.74]}\end{array}$ & $\begin{array}{c}14.93 \\
{[13.77 ; 16.10]}\end{array}$ & $\begin{array}{c}14.24 \\
{[13.09 ; 15.39]}\end{array}$ & $\begin{array}{c}11.65 \\
{[10.46 ; 12.84]}\end{array}$ & $\begin{array}{c}13.96 \\
{[12.54 ; 15.37]}\end{array}$ & $\begin{array}{c}13.13 \\
{[10.64 ; 15.61]}\end{array}$ \\
\hline A.U. Weekly-Sleep & $\begin{array}{c}13.67 \\
{[10.13 ; 17.20]}\end{array}$ & $\begin{array}{c}15.94 \\
{[14.55 ; 17.33]}\end{array}$ & $\begin{array}{c}14.39 \\
{[13.12 ; 15.66]}\end{array}$ & $\begin{array}{c}12.20 \\
{[10.95 ; 13.45]}\end{array}$ & $\begin{array}{c}11.87 \\
{[10.69 ; 13.06]}\end{array}$ & $\begin{array}{c}11.60 \\
{[10.44 ; 12.76]}\end{array}$ & $\begin{array}{c}13.00 \\
{[11.83 ; 14.17]}\end{array}$ & $\begin{array}{c}12.73 \\
{[11.57 ; 13.89]}\end{array}$ & $\begin{array}{c}10.33 \\
{[9.13 ; 11.52]}\end{array}$ & $\begin{array}{c}12.15 \\
{[10.70 ; 13.59]}\end{array}$ & $\begin{array}{c}11.88 \\
{[9.74 ; 14.01]}\end{array}$ \\
\hline A.U. Weekly-Fatigue & $\begin{array}{c}13.33 \\
{[10.97 ; 15.69]}\end{array}$ & $\begin{array}{c}16.20 \\
{[15.14 ; 17.26]}\end{array}$ & $\begin{array}{c}15.03 \\
{[13.69 ; 16.39]}\end{array}$ & $\begin{array}{c}12.32 \\
{[11.25 ; 13.39]}\end{array}$ & $\begin{array}{c}11.53 \\
{[10.37 ; 12.70]}\end{array}$ & $\begin{array}{c}12.42 \\
{[11.33 ; 13.52]}\end{array}$ & $\begin{array}{c}15.67 \\
{[14.38 ; 16.97]}\end{array}$ & $\begin{array}{c}13.69 \\
{[12.59 ; 14.80]}\end{array}$ & $\begin{array}{c}11.91 \\
{[10.76 ; 13.06]}\end{array}$ & $\begin{array}{c}14.22 \\
{[12.86 ; 15.60]}\end{array}$ & $\begin{array}{c}12.79 \\
{[10.46 ; 15.13]}\end{array}$ \\
\hline A.U. Weekly-Stress & $\begin{array}{c}7.11 \\
{[5.12 ; 9.11]}\end{array}$ & $\begin{array}{c}12.10 \\
{[10.38 ; 13.82]}\end{array}$ & $\begin{array}{c}10.49 \\
{[8.99 ; 11.99]}\end{array}$ & $\begin{array}{c}9.64 \\
{[7.76 ; 11.52]}\end{array}$ & $\begin{array}{c}8.92 \\
{[7.22 ; 10.62]}\end{array}$ & $\begin{array}{c}9.07 \\
{[7.29 ; 10.85]}\end{array}$ & $\begin{array}{c}10.59 \\
{[8.56 ; 12.61]}\end{array}$ & $\begin{array}{c}8.02 \\
{[6.84 ; 9.20]}\end{array}$ & $\begin{array}{c}6.58 \\
{[5.53 ; 7.64]}\end{array}$ & $\begin{array}{c}7.71 \\
{[6.64 ; 8.77]}\end{array}$ & $\begin{array}{c}7.21 \\
{[5.76 ; 8.65]}\end{array}$ \\
\hline
\end{tabular}

Note. DOMS - delayed onset muscle soreness; A.U. - arbitrary units
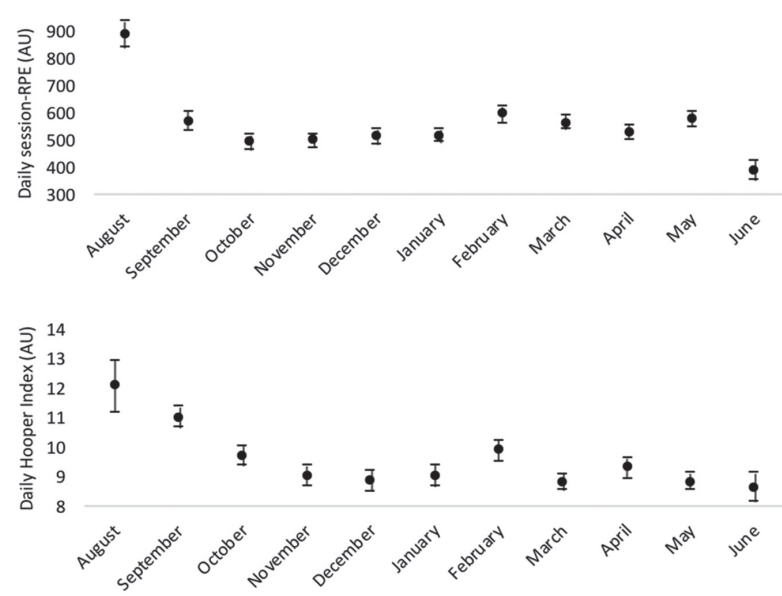

Note. RPE - rate of perceived exertion.

Figure 1. Mean (95\% confidence intervals) daily session-RPE and Hooper Index over the season.
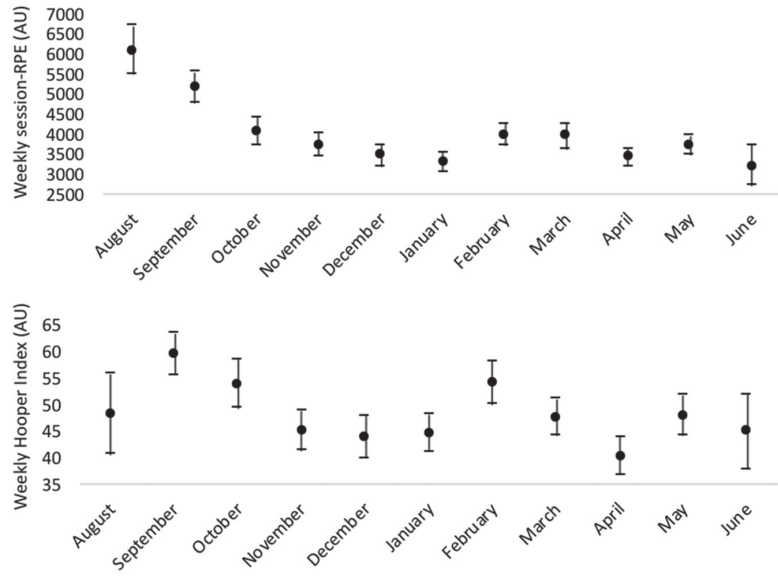

Note. RPE - rate of perceived exertion.

Figure 2. Mean (95\% confidence intervals) weekly session-RPE and Hooper Index over the season. 
Table 3. Correlations (rho) between daily Hooper categories and daily session-RPE and between weekly Hooper categories and weekly session-RPE over the season

\begin{tabular}{|c|c|c|c|c|c|c|c|c|c|c|c|}
\hline & August & September & October & November & December & January & February & March & April & May & June \\
\hline \multicolumn{12}{|c|}{ Daily session-RPE and daily Hooper categories on the following day } \\
\hline A.U. DOMS & $.452^{\mathrm{b}}$ & $.181^{\mathrm{b}}$ & $.335^{\mathrm{b}}$ & .032 & $.325^{\mathrm{b}}$ & .088 & $-.296^{b}$ & .044 & .003 & $-.230^{\mathrm{b}}$ & $.296^{\mathrm{b}}$ \\
\hline A.U. Sleep & .203 & -.005 & $.211^{b}$ & -.029 & .041 & .002 & -.070 & -.002 & -.029 & .031 & .061 \\
\hline A.U. Fatigue & $.393^{\mathrm{b}}$ & $.189^{\mathrm{b}}$ & $.378^{\mathrm{b}}$ & .095 & $.230^{\mathrm{b}}$ & .028 & $.275^{b}$ & $.307^{\mathrm{b}}$ & .073 & $.250^{\mathrm{b}}$ & $.292^{\mathrm{b}}$ \\
\hline A.U. Stress & .121 & .058 & -.085 & $-.199^{b}$ & -.107 & $-.154^{a}$ & $-.144^{a}$ & $-.187^{b}$ & $-.228^{b}$ & $-.153^{b}$ & -.098 \\
\hline \multicolumn{12}{|c|}{ Weekly Hooper categories and weekly session-RPE } \\
\hline A.U. DOMS & $.860^{\mathrm{b}}$ & $.355^{\mathrm{a}}$ & $.612^{\mathrm{b}}$ & $.283^{\mathrm{a}}$ & $.612^{\mathrm{b}}$ & $.530^{\mathrm{b}}$ & $.478^{\mathrm{b}}$ & $.316^{\mathrm{a}}$ & $.472^{\mathrm{b}}$ & $.556^{\mathrm{b}}$ & $.669^{b}$ \\
\hline A.U. Sleep & .217 & $.414^{\mathrm{b}}$ & $.521^{\mathrm{b}}$ & .236 & $.375^{\mathrm{b}}$ & $.371^{\mathrm{a}}$ & .139 & $.386^{\mathrm{b}}$ & .140 & $.285^{a}$ & $.576^{\mathrm{b}}$ \\
\hline A.U. Fatigue & $.863^{b}$ & $.356^{\mathrm{a}}$ & $.707^{\mathrm{b}}$ & $.606^{b}$ & $.521^{\mathrm{b}}$ & $.421^{\mathrm{b}}$ & $.525^{\mathrm{b}}$ & $.547^{\mathrm{b}}$ & $.377^{\mathrm{b}}$ & $.599^{b}$ & $.707^{\mathrm{b}}$ \\
\hline A.U. Stress & .090 & $.349^{a}$ & .073 & -.202 & .092 & .007 & -.077 & .016 & -.116 & -.100 & .347 \\
\hline
\end{tabular}

Note. DOMS - delayed onset muscle soreness; RPE - rate of perceived exertion; HI - Hooper Index. ${ }^{a}$ significant correlation at $p<.05$.

${ }^{\mathrm{b}}$ Significant correlation at $\mathrm{p}<.01 ;$ A.U. - arbitrary units

\section{Discussion and conclusion}

This study analyzed the correlation between internal training load (session-RPE) and wellness status (Hooper questionnaire) measured daily and weekly over a professional basketball season. Considering that some variables related to wellness status could present a delayed response to training stimulus, we hypothesized that the weekly measures would present a stronger relationship than the daily measures. This study results confirmed this hypothesis, showing moderate-to-large correlations between session-RPE and Hooper categories for weekly measures compared to small-tomoderate correlations for daily measures. These differences in correlation levels are mostly attributable to DOMS and fatigue categories, rather than sleep quality and stress.

This study results for daily measures' correlations corroborate the findings of Thorpe et al. (2015) and Clemente et al. (2017) in soccer players, which also reported higher correlation values to training load for DOMS and fatigue compared to stress and sleep quality, although all these correlations were also small-to-moderate. These data support the highest sensitivity of DOMS and perceived fatigue for variations in perceived training load. Indeed, these variables may be related to each other and are associated to physical strain players experience during training sessions and matches. This rationale adds support to the usefulness of sessionRPE for estimating objective training load (Manzi, et al., 2010; Scanlan, et al., 2014). On the other hand, stress and sleep quality may be more influenced by psychological out-of-training factors and, therefore, showed weaker correlations with session-RPE. In fact, stress sources may be quite independent of the training load mainly considering contextual dimensions as negative aspects of organizational systems and culture, worries about performance expectations and standards, career development concerns, negative aspects of interpersonal relationships, demanding nature of work itself, or problems associated with the work/non-work interface (Noblet \& Gifford, 2002). Moreover, the experience of players also contribute to a different perspective about the stress factors, meaning more experienced players seems to indicate the organizational dimensions as greater stressor factors than the competitive ones or performance itself (Hanton, Fletcher, \& Coughlan, 2005). Similarly to the stress dimension, sleep quality is also somehow independent of the training load, considering that concurrent factors as the level of competition before the night of sleep, the perception of stress and the travels seems to influence quality of sleep (Gupta, Morgan, \& Gilchrist, 2017).

Although the session-RPE is a psychophysiological variable (Eston, 2012), it seems that stress and sleep quality were only slightly influenced by the perceived training load, while physical parameters were stronger associated.

The comparison of strength of correlations between the daily and weekly measures showed stronger correlations between session-RPE and all wellness categories for weekly measures, except for stress. Possibly, the accumulated load may increase the overall perception of DOMS and fatigue of that period (week), mainly considering that a high load impact seems to produce a delayed effect in the players' responses (from 24 to 76 hours) (Pliauga, et al., 2015).

The stronger correlation between weekly session-RPE and DOMS and fatigue reinforced the importance of these two variables in monitoring the impact of training load on athletes' physical wellness. Although some studies reported the sensitivity of fatigue scales to daily variations in training load (Mielgo-Ayuso, et al., 2017; Thorpe, et al., 2017), 
the delayed muscle soreness provoked by muscle damage may have increased DOMS weekly correlations, as well as the sensation of fatigue. In fact, Buchheit et al. (2013) found different tendencies for daily fatigue and DOMS correlations with sessionRPE in Australian footballers. While fatigue showed small positive correlations with session-RPE (i.e., the higher the perceived load, the higher the fatigue), DOMS presented a moderate inverse correlation with session-RPE, suggesting that training load did not increase DOMS on the following day (i.e., no influence after only $24 \mathrm{~h}$ ). Thus, a daily analysis of DOMS and fatigue may underestimate actual impact of training load on athletes' physical conditions. Conversely, although significant correlations between daily session-RPE and stress were smallto-moderate, daily measures presented more significant correlations than weekly measures over the months, especially at the end of the season. This suggests that stress levels may be more associated to training load at the end of the season, when athletes are experiencing an accumulated effect of training and competition demands and are approaching to more important/decisive matches. Additionally, daily measures seem to better reflect the impact of training load on stress levels, possibly due to a more momentary (not delayed) impact of training on this variable.

Considering that players' experience may influence aspects such as stress/anxiety, differences in athletes ages and level of competition may generate different relationships between the perceived training load and wellness categories, which limits the generalization of results to other basketball categories. In addition, future studies should investigate the relationship between wellness categories and the external training load in professional basketball players, in order to confirm this study results.

We can conclude that DOMS and fatigue are closer associated to session-RPE than stress and sleep quality in professional basketball players. In addition to wellness daily assessment, weekly analyses may help coaches to better understand the impact of training load on athletes' physical wellness (DOMS and fatigue).

\section{References}

Anderson, L., Triplett-McBride, T., Foster, C., Doberstein, S., \& Brice, G. (2003). Impact of training patterns on incidence of illness and injury during a women's collegiate basketball season. Journal of Strength and Conditioning Research, 17(4), 734-738.

Borg, G. (1998). Perceived exertion and pain scales. Champaign, IL: Human Kinetics.

Bourdon, P.C., Cardinale, M., Murray, A., Gastin, P., Kellmann, M., Varley, M. C., ..., \& Cable, N.T. (2017). Monitoring athlete training loads: Consensus statement. International Journal of Sports Physiology and Performance, 12(Suppl. 2), S2-161-S2-170. doi: 10.1123/IJSPP.2017-0208

Buchheit, M., Racinais, S., Bilsborough, J.C., Bourdon, P.C., Voss, S.C., Hocking, J., ..., \& Coutts, A.J. (2013). Monitoring fitness, fatigue and running performance during a pre-season training camp in elite football players. Journal of Science and Medicine in Sport, 16(6), 550-555. doi: 10.1016/j.jsams.2012.12.003

Clemente, F.M., Mendes, B., Nikolaidis, P.T., Calvete, F., Carriço, S., \& Owen, A.L. (2017). Internal training load and its longitudinal relationship with seasonal player wellness in elite professional soccer. Physiology and Behavior, 179, 262-267. doi: 10.1016/j.physbeh.2017.06.021

Cormack, S.J., Newton, R.U., \& McGuigan, M.R. (2008). Neuromuscular and endocrine responses of elite players to an Australian rules football match. International Journal of Sports Physiology and Performance, 3(3), 359-374. doi: 10.1123/ijspp.3.3.359

Eston, R. (2012). Use of ratings of perceived exertion in sports. International Journal of Sports Physiology and Performance, 7(2), 175-182.

Foster, C., Florhaug, J.A., Franklin, J., Gottschall, L., Hrovatin, L.A., Parker, S., ..., \& Dodge, C. (2001). A new approach to monitoring exercise training. Journal of Strength and Conditioning Research, 15(1), 109-115.

Gupta, L., Morgan, K., \& Gilchrist, S. (2017). Does elite sport degrade sleep quality? A systematic review. Sports Medicine, 47(7), 1317-1333. doi: 10.1007/s40279-016-0650-6

Haddad, M., Chaouachi, A., Wong, D.P., Castagna, C., Hambli, M., Hue, O., \& Chamari, K. (2013). Influence of fatigue, stress, muscle soreness and sleep on perceived exertion during submaximal effort. Physiology and Behavior, 119, 185-189. doi: 10.1016/j.physbeh.2013.06.016

Halson, S.L. (2014). Monitoring training load to understand fatigue in athletes. Sports Medicine, 44(2), 139-147. doi: $10.1007 / \mathrm{s} 40279-014-0253-\mathrm{z}$

Hanton, S., Fletcher, D., \& Coughlan, G. (2005). Stress in elite sport performers: A comparative study of competitive and organizational stressors. Journal of Sports Sciences, 23(10), 1129-1141. doi: 10.1080/02640410500131480 
Hooper, S.L., \& Mackinnon, L.T. (1995). Monitoring overtraining in athletes. Sports Medicine, 20(5), 321-327. doi: 10.2165/00007256-199520050-00003

Hopkins, K.D., Hopkins, B.R., \& Glass, G.V. (1996). Basic statistics for the behavioral sciences. Boston: Allyn and Bacon.

Ispirlidis, I., Fatouros, I.G., Jamurtas, A.Z., Nikolaidis, M.G., Michailidis, I., Douroudos, I., ..., \& Taxildaris, K. (2008). Time-course of changes in inflammatory and performance responses following a soccer game. Clinical Journal of Sport Medicine, 18(5), 423-431. doi: 10.1097/JSM.0b013e3181818e 0b

Malone, J.J., Di Michele, R., Morgans, R., Burgess, D., Morton, J.P., \& Drust, B. (2015). Seasonal training-load quantification in elite English Premier League soccer players. International Journal of Sports Physiology and Performance, 10(4), 489-497. doi: 10.1123/ijspp.2014-0352

Malone, J.J., Lovell, R., Varley, M.C., \& Coutts, A.J. (2017). Unpacking the black box: Applications and considerations for using GPS devices in sport. International Journal of Sports Physiology and Performance, 12(Suppl. 2), S2-18-S2-26. doi: 10.1123/ijspp.2016-0236

Manzi, V., D’Ottavio, S., Impellizzeri, F.M., Chaouachi, A., Chamari, K., \& Castagna, C. (2010). Profile of weekly training load in elite male professional basketball players. Journal of Strength and Conditioning Research, 24(5), 1399-1406. doi: 10.1519/JSC.0b013e3181d7552a

Mielgo-Ayuso, J., Zourdos, M.C., Clemente-Suárez, V.J., Calleja-González, J., \& Shipherd, A.M. (2017). Can psychological well-being scales and hormone levels be used to predict acute performance of anaerobic training tasks in elite female volleyball players? Physiology and Behavior, 180, 31-38. doi: 10.1016/j.physbeh.2017.08.008

Moreira, A., Arsati, F., Cury, P.R., Franciscon, C., Simões, A.C., de Oliveira, P.R., \& de Araújo, V.C. (2008). The impact of a 17-day training period for an international championship on mucosal immune parameters in top-level basketball players and staff members. European Journal of Oral Sciences, 116(5), 431-437. doi: 10.1111/j.16000722.2008.00558.x

Noblet, A.J., \& Gifford, S.M. (2002). The sources of stress experienced by professional Australian footballers. Journal of Applied Sport Psychology, 14(1), 1-13. doi: 10.1080/10413200209339007

O’Donoghue, P. (2012). Statistics for sport and exercise studies: An introduction. London, New York: Routledge Taylor \& Francis Group.

Pliauga, V., Kamandulis, S., Dargevičiūtè, G., Jaszczanin, J., Klizienė, I., Stanislovaitienė, J., \& Stanislovaitis, A. (2015). The effect of a simulated basketball game on players' sprint and jump performance, temperature and muscle damage. Journal of Human Kinetics, 46(1), 167-175. doi: 10.1515/hukin-2015-0045

Scanlan, A.T., Neal, W., Tucker, P.S., \& Dalbo, V.J. (2014). The relationships between internal and external training load models during basketball training. Journal of Strength and Conditioning Research, 28(9), 2397-2405.

Thorpe, R.T., Strudwick, A.J., Buchheit, M., Atkinson, G., Drust, B., \& Gregson, W. (2015). Monitoring fatigue during the in-season competitive phase in elite soccer players. International Journal of Sports Physiology and Performance, 10(8), 958-964. doi: 10.1123/ijspp.2015-0004

Thorpe, R.T., Strudwick, A.J., Buchheit, M., Atkinson, G., Drust, B., \& Gregson, W. (2017). The influence of changes in acute training load on daily sensitivity of morning-measured fatigue variables in elite soccer players. International Journal of Sports Physiology and Performance, 12(2), S2-107-S2-113. doi: 10.1123/ijspp.2016-0433

Submitted: February 7, 2018

Accepted: May 23, 2019

Published Online First: June 4, 2020

Corresponding author:

Filipe Manuel Clemente

Complexo Desportivo e Lazer de Melgaço -

Monte de Prado, 4960-320, Melgaço, Portugal

e-mail: filipe.clemente5@gmail.com 